\title{
Male sling for urinary incontinence after radical prostatectomy: inicial results
}

\author{
Cassini. M. F. ${ }^{1, ~ *, ~ M a z z o . ~ A ~}{ }^{2}$ Tucci Jr. S. ${ }^{1}$ \\ ${ }^{1}$ Department of Surgery and Anatomy, Faculty of Medicine of Ribeirao Preto, University of Sao Paulo, Brazil \\ ${ }^{2}$ Faculty of Nursing of Ribeirao Preto, University of Sao Paulo, Brazil
}

\section{Email address:}

marcelo.cassini@globo.com(Cassini. M. F.), amazzo@eerp.usp.br(Mazzo. A), stucci49@gmail.com(Tucci Jr. S.)

\section{To cite this article:}

Cassini. M. F., Mazzo. A, Tucci Jr. S. Male Sling for Urinary Incontinence after Radical Prostatectomy: Inicial Results. Science Research. Vol. 1, No. 3, 2013, pp. 35-38. doi: 10.11648/j.sr.20130103.11

\begin{abstract}
Introduction: Urinary incontinence after radical prostatectomy is a major complication with profound impact on the social life of the patients. we report inicial cases of patients treated with male sling implant. Methods: Eight patients with urinary incontinence after radical prostatectomy underwent to male sling (Argus- $\mathrm{T}^{\circledR}$ - Promedon) implant. We analyzed the age, the number of transurethral resection previously of the implant, the degree of incontinence before the sling (by urodynamics) and the subjective satisfaction with the surgery by telephone. Results: The patients (08) were submitted to a radical retropubic prostatectomy for localized prostate cancer. All incontinent patients developed stenosis of vesicourethral anastomosis and were underwent transurethral resection of the anastomotic fibrosis (ranging from one to three procedures). Five patients had moderate to severe urinary incontinence before the procedures. After the implant, five patients had no improvement in the degree of incontinence, three patients had a subjective improvement, two of them were completely dry. These, previously, had the lowest degree of incontinence in the objective analysis (urodynamics). Conclusion: The urinary incontinence after prostatectomy is a morbidity with challenging treatment. The male sling is a good method for mild cases and motivated patients, not being the first choice for more severe cases.
\end{abstract}

Keywords: Male Sling, Urinary Incontinence, Radical Prostatectomy Complication

\section{Introduction}

The urinary incontinence in men is most caused by iatrogenic induced insufficiency of the external urethral sphincter injury by transurethral resection of the prostate or after radical prostatectomy (1). As reported in the literature, the rate of urinary incontinence after radical prostatectomy, range from 1 to $90 \%(2-4)$.

Definitions of continence are variable from total dryness to the use of multiple incontinence pads per day. The desire for social continence is strong, and many different therapeutic innovations have been designed for this purpose.

An important step in the evaluation of incontinent men is active discussion between the physician and the patient. The initial option in the treatment of post-surgical incontinence could be pelvic floor training and electrostimulation sometimes combined with biofeedback $(5,6)$. If primary conservative therapy fails and the findings of a further diagnostic evaluation (cistoscopy; urodynamic) warrant surgery, a variety of surgical procedures are avaiable to treat postoperative urinary incontinence, like sub-urethral male sling or artificial urethral sphincter, as many others (7)

The artificial urinary sphincter (AUS) remains the gold standard of treatment for intractable urinary incontinence in men, despite its rather high complication rate, costs and the availability of newer and less invasive techniques like the male slings (8).

\section{Material and Methods}

This initial retrospective study was performed with the data of eight patients having significant urinary incontinence, developed after radical prostatectomy. The patients were underwent to male sling (Argus- $\mathrm{T}^{(\mathrm{R})}-$ Promedon) implant, in 2011, range from two to five years after the initial prostate procedure.

We analyzed the age, the number of transurethral resection of the anastomosis fibrosis (TURA) previously of the implant, the degree of incontinence before the sling (by urodynamics) and the subjective satisfaction with the surgery by telefone six months later.

Surgical technique: the surgery was performed under 
spinal or general anaesthesia, and a 16-Fr Foley catheter is passed transurethral whilst the patient is placed in the standard lithotomy position. A 6-cm medial vertical perineal skin incision below the inferior border of the pubic symphysis was carried out in order to expose the bulbospongiosus muscle, than to expose the perineal aponeurosis at the top of the triangular space delimited laterally by each ischiocavernous muscle and medial to the bulbospongiosus. The crura of the cavernous bodies are clearly identified whilst ensuring that the central tendon and the bulbospongiosus muscle remain intact. A short 2 $\mathrm{mm}$ incision through the pelvic fascia afforded access to the obturator muscle just under the ischiopubic ramus bone is done. A bilateral stab incision was made at the top of the thigh, $4 \mathrm{~cm}$ from the median line and $4 \mathrm{~cm}$ below the major adductor longus muscle. The transobturator puncture was an outside inside with a Hemet needle. The end point of the puncture was the opening in the pelvic fascia. After sling attachment to the needle, it was pulled back in order to correctly implant the sling. The same procedure was repeated on the other side. The sling was sutured to the bulbospongiosus muscle with non-absorbable sutures, and then pulled firmly from each side in order to obtain a $2 \mathrm{~mm}$ visible mark on the bulbospongiosus muscle. The perineal body was not dissected, but in cases of rolling of the inferi- or edge of the sling on the bulb, the bulb was dissected just enough to apply in under the sling, then sutured to the sling. The presence of clear urine and cystoscopy confirm that the urethra and bladder are intact. To stablish the retrograde leak-point pressure (RLPP) a cystoscopic sheath is used. The Argus sling is progressively adjusted by tensioning the silicone columns through the washers to achieve a RLPP measurement ranging within $30-50 \mathrm{cmH}_{2} \mathrm{O}$ and then subsequently the perianal incision is closed. Before closing the lateral incisions, the end of the columns are left in the subcutaneous to facilitate postoperative adjustments if necessary. The Foley catheter is generally left in situ for 2 days.

\section{Results}

All eight patients had previously undergone to radical retropubic prostatectomy for localized prostate cancer. (Table 1). The patients developed stenosis of vesicourethral anastomosis and were underwent transurethral resection of the anastomotic fibrosis (ranging from one to three procedures). Five patients had moderate to severe urinary incontinence before the procedures. After the implant, five patients had no improvement in the degree of incontinence. Three patients had a subjective improvement, two of them were completely dry.

Table 1. Summary of the analyzed data and results.

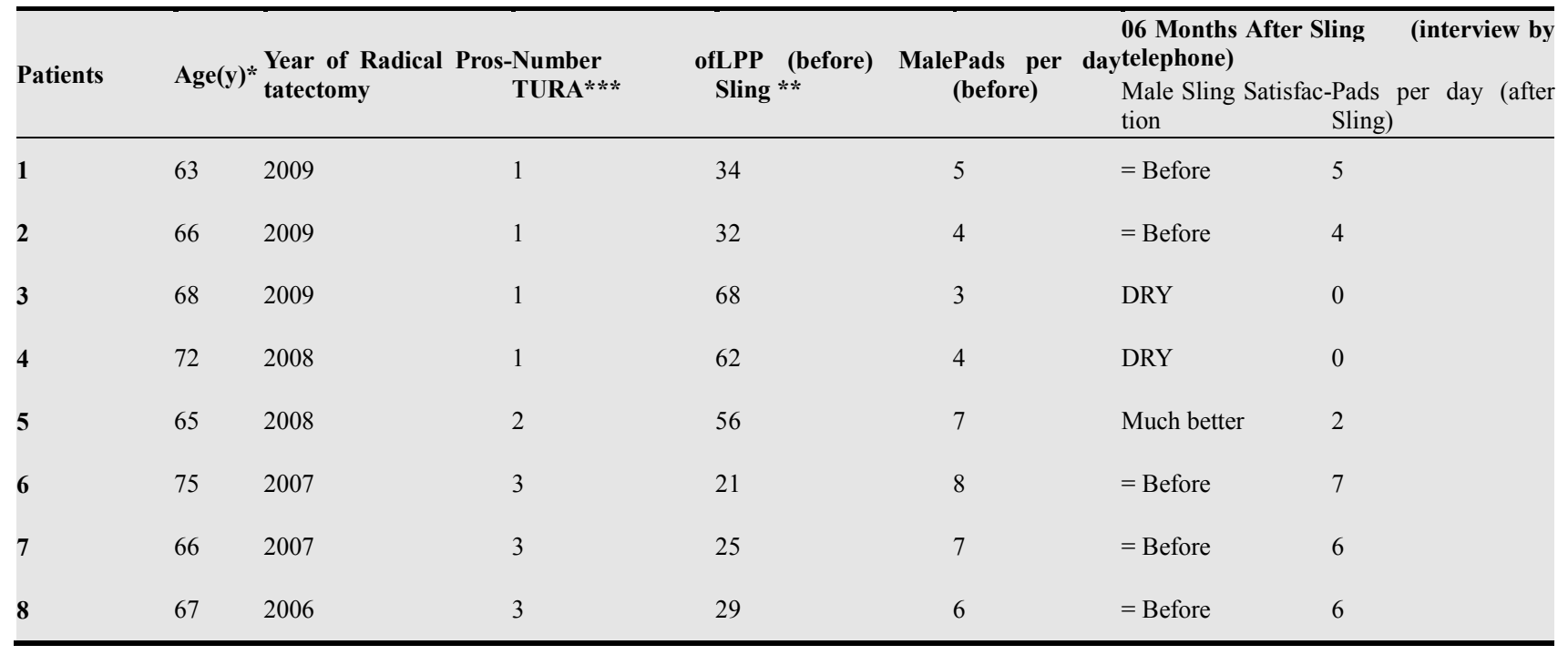

*Age in years $(\mathrm{y})$ at time of the Male Sling procedure ; **LPP - Leak Point Pressure $\quad * * *$ TURA - Transurethral resection of anastomosis fibrosis ; = Before (equal before)

These patients, previously, had the lowest degree of incontinence in the objective analysis (urodynamics). Patients age was not correlated with the success rate of the procedure however, the number of anastomosis fibrosis resections was inversely proportional to the good results. The devices were removed from three patients who had no improvement in incontinence because of perineal pain (02) and urethral erosion (01). The erosion of the urethra was treated conservatively with an indwelling silicone cateter.

\section{Discussion}

The treatment of male urinary incontinence (UI) after radical prostatectomy ramains a challenge. Some of current surgical therapies for UI in men include the artificial urinary sphincter (AUS) as the gold standard for postprostatectomy UI (9-10); the minimally invasive adjustable balloons, the bulking agentes and the sub-urethral slings (adjustable or bone fixed) $(8,11,12)$. 
Recently (2012) Wang R, McGuire EJ, et al published a study (13) with 318 AUS implantation devices showing that more than half of paitents required additional procedures, like revision. Median time to first revision or explantation was (20 months) less than 2 years, and the most common indication was recurrent incontinence (57\%). These failures, combined with the high costs are responsible for the decrease in AUS implantation noted after the 2003 introduction of male urethral slings.

The 2012 European Association of Urology (EAU) guideline on surgical treatment of urinary incontinence shows that there is low-level evidence that male sling implantation results in cure or improves post-prostatectomy incontinence at up to 3 years (14). Male slings appear to be less effective for men with severe incontinence, previous radiotherapy, or previous urethral stricture surgery. Possible harms include voiding disfunction, device erosion and chronic pain $(15,16)$.

This work has an main criticismo the small number of patients studied, but even then, there was an excelente correlation with the results found in literature. The adjustable suburethral sling is cheaper than the artificial urinary sphincter, $25 \%$ of patients were dry, $12.5 \%$ showed significant improvement of the urinary incontinence, $62,5 \%$ of patients had no improvement and in $12,5 \%$ of cases there was a need for explantation of the device because of urethral erosion. Patients undergoing to radiotherapy were not included in the study.

Unlike female slings that are placed as a tension-free support under the mid-urethra, male slings need to generate a slight, permanent urethral resistance to achieve continence. To avoid overcorrection and obstruction and to enable the sling to adapt to developing functional or anatomical changes in the patients, adjustable systems are preferable(17).

Compressing the bulbar urethra in an attempt to provide urinary continence was first suggested by Marshall et al. in 1946(18); they proposed that with compression and elevation of the perineal area, sphincter support could be provided, thus improving its function. Very few authors had previously reported on the use of bulbourethral sling procedures whereby the sling is transferred to the abdomen using needles (19-22) until Schaeffer et al. (23) in 1998 published a series of 64 patients. They reported a $64 \%$ cure/improvement rate ( $0-2$ pads per day) after a median follow-up of 18,1 months and a $75 \%$ success rate after adjustment-operations were made in $27 \%$. However, longer term results were less satisfactory with 24 patients $(42 \%)$ considered cured, 17 (30\%) wearing 1-2 pads/day and 16 patients $(28 \%)$ requiring $\geq 2$ pads/day after a mean followup of 48 months. After the report from Schaeffer et al. (23), other centres considered bulbourethral sling procedures as a realistic alternative for the treatment of stress urinary incontinence after radical prostatectomy. In addition, the sling is much less expensive than the AUS.

Subsequently, various slings were marketed for postprostatectomy and autologous materials (24). A different technique based on the concept originally proposed by Kaufman et al. in 1970 (25), which compresses the bulbous urethra in the perineum without entering the abdomen, was later applied by Madjar et al. (26) in 2001 and subsequently by Comiter (27). This technique used bone anchors to fix a polypropylene mesh for urethral compression and produced very encouraging results in the short term, with a $90 \%$ cure/improvement rate after a mean follow-up of 12 months. After, Castle et al. (11) reported their medium-term experience in 38 patients treated with the bone-anchored Invance sling with a mean follow-up of 18 months and a success rate (defined as no more than 1 pad/day) of only $39,5 \%$. The success of Invance seems to depend on the preoperative incontinence grade as well as the duration of the follow-up. Rehder and Gozzi introduced the Advance transobturator sling in 2007 (12), as a new non-obstructive tape for the treatment of SUI after radical prostatectomy. This first clinical series included 20 patients, with reports that $40 \%$ of the patients were cured and $30 \%$ had improved incontinence. However, their follow up was only 6 weeks.

Gozzi et al. (28) recently published a further report on the Advance sling in a series of 67 patients with a follow-up of 3 months. The cure rate was $52 \%$ with further $38 \%$ improved. Their re-operation rate was $11 \%$.

Hubner et al in 2010 showed promising results in 101 patients after a median follow-up of 2.2 years despite the complicated presentation of patients, where $33.7 \%$ of patients had previous failed implantations with other devices for their SUI and a significant proportion had undergone a adjunctive procedures, i.e. radiation $(21.8 \%)$, repeated bladder neck incisions or internal urethrotomy (29.7\%) which tend to further complicate efforts to produce a satisfactory outcome after any treatment for SUI.

Despite this difficulty, the Argus sling achieved high continence rates $(79.2 \%$ dry, pad test $0-1 \mathrm{~g})$ with relatively low complication rates (15.8\% device removals). Dr. Hubner states that as shown in the comparison of different followups it appears that Argus sling result are durable. Nevertheless, in patients who have not previously undergone and failed other SUI surgeries, better results may be possible. As such, his learning curve was represented by the first 22 cases, where accumulated experience established a suitable initial degree of tension to apply, based on an appropriate intraoperative adjustment of the RLPP during the initial implant procedure.

As the data in the literature, our study showed that patients with more severe incontinence degree and those with more severe stenosis of anastomosis showed the worst results.

\section{Conclusion}

The urinary incontinence after prostatectomy is a morbidity with challenging treatment. The male sling is a good method for mild cases and motivated patients, not being the first choice for more severe cases. 


\section{References}

[1] Nitti VW, Blaivas JG. Urinary Incontinence. In: Walsh P, Retik A, Vaughan ED, Wein A, editors. Campbell's Urology. New York: Saunders; 2010. pp. 2047-2049.

[2] Burkhard FC, Kessler TM, Fleischmann A, Thalmann GN, Schu-macher M, Studer UE. Nerve sparing open radical retropubic prostatectomy - does it have an impact on urinary continence? J Urol. 2006;176(1):189-195.

[3] Rudy DC, Woodside JR, Crawford ED. Urodynamic evaluation of incontinence in patients undergoing modified Campbell radical retropubic prostatectomy: a prospective study. J Urol. 1984;132(4):708-712.

[4] Wei JT, Dunn RL, Sandler HM, et al. Comprehensive comparison of health-related quality of life after contemporary therapies for localized prostate cancer. J Clin Oncol. 2002;20(2):557-566.

[5] Hunter KF, Moore KN, Cody DJ, Glazener CM. Conservative management for postprostatectomy urinary incontinence. Cochrane Database Syst Rev. 2004;(2) CD001843.

[6] Moore KN, Cody DJ, Glazener CM. Conservative management for post prostatectomy urinary incontinence. Cochrane Database Syst Rev. 2001;(2) CD001843.

[7] Bross S, Kwon ST, Peter S, Honeck P. New techniques for surgical treatment of postoperative male stress incontinence. Urologe A. 2007;46(3):257-263.

[8] Hubner WA, Schlarp OM. Treatment of incontinence after prostatectomy using a new minimally invasive device: adjustable continence therapy. BJU Int.2005;96(4):587-594.

[9] Tse V, Stone AR. Incontinence after prostatectomy: the artificial sphincter. BJU Int. 2003; 92: 886-889.

[10] Schaeffer AJ. Editorial: prostatectomy incontinence. J Urol 2002; 167: 602 .

[11] Castle EP, Andrews PE, Itano N, Novicki DE, Swanson SK, Ferrigni RG. The male sling for post-prostatectomy incontinence: mean follow up of 18 months. J Urol 2005;173: $1657-1660$.

[12] Rehder P, Gozzi C. Transobturator sling suspension for male urinary incontinence including post radical prostatectomy. Eur Urol 2007;52: 860-866.

[13] Wang R, McGuire EJ, He C, Faeber GJ, Latini JM. Longterm outcomes after primary failures of artificial urinary sphincter implantation. Urology 2012; 79: 922-928.

[14] Lucas $M$ et al. European Association of Urology (EAU) guidelines on surgical treatment of urinary incontinence. Eur Urol (2012) http://dx.doi.org/10.1016/j.eururo.2012.09.023

[15] Bauer RM, Soljanik I, Fullhase C, et al. Results of the AdVance transobturador male sling after radical prostatectomy and adjuvant radiotherapy. Urology 2011;77:474-479.

[16] Rehder P, Mitterberger M, Pichler R, et al. Two year outcome of the transobturator retroluminal repositioning sling in the treatment of male stress urinary incontinence [Abstract 994]. Eur Urol Suppl 2011;10:309.

[17] Hubner WA, Gallistl H, Rutkowski M, Huber ER. Adjustable bulbourethral male sling: experience after 101 cases of moderate-to-severe male stress urinary incontinence. BJU Int. 2010;107:777-782.

[18] Marshall V, Pollack R, Miller CH. Observation on urinary dysfunction after excision of the rectum. J Urol 1946;55:409-416.

[19] Raz S, McGuire EJ, Ehrlich RM et al. Fascial sling to correct male neurogenic sphincter incompetence: the McGuire/Raz approach. J Urol 1988; 139:528-531.

[20] Mizuo T, Tanizawa A, Yamada T, Ando M, Oshima H. Sling operation for male stress incontinence by utilizing modified Stamey technique. Urology 1992; 39: 211-214.

[21] Stamey T. Perineal compression of the corpus spongiosum of the bulbar urethra. An operation for post radical prostatectomy incontinence. J Urol 1994; 151: A90.

[22] Shoukry MS, El-Salmy S. Urethral needle suspension for male urinary incontinence. Scand J Urol Nephrol 1997; 31: 267-270.

[23] Schaeffer AJ, Clemens CJ, Ferrari M, Stamey TA. The male bulbourethral sling procedure for post-radical prostatectomy incontinence. J Urol 1998; 159: 1510-1515.

[24] Abrams P, Cardozo L, Khoury S, Wein A. Incontinence: management. In $3^{\text {rd }}$ International Consultation on Incontinence 2004; 2 : 1252 .

[25] Kaufman JJ. A new operation for male incontinence. Surg Gynecol Obstet 1970; 131: 295-299.

[26] Madjar S, Jacoby K, Giberti C et al. Bone anchored sling for the treatment of post-prostatectomy incontinence. J Urol 2001; 165: 72-76.

[27] Comiter CV. The male sling for stress urinary incontinence: a prospective study. J Urol 2002; 167: 597-601.

[28] Gozzi C, Becker AJ, Bauer R, Bastian PJ. Early results of transobturator for male urinary incontinence following radical prostatectomy. Eur Urol 2008; 54: 960-961. 